\title{
Polymerase chain reaction with lesion scrapping for the diagnosis of human American tegumentary leishmaniasis
}

\author{
Eneide Aparecida Sabaini Venazzi, Andréa Claudia Bekner Silva Roberto, \\ Ione Parra Barbosa-Tessmann, Paulo Donizeti Zanzarini, Maria Valdrinez Campana \\ Lonardoni, Thaís Gomes Verzignassi Silveira ${ }^{+}$
}

\author{
Departamento de Análises Clínicas, Departamento de Bioquímica, Universidade Estadual de Maringá, Av. Colombo 5790, \\ 87020-900 Maringá, PR, Brasil
}

\begin{abstract}
The objective of this work was to compare the polymerase chain reaction (PCR) using lesion scrapping with other conventional techniques for the diagnosis of the American tegumentary leishmaniasis (ATL). For this, patients with cutaneous lesions suspected to be ATL were studied. The DNA was amplified with the MPIL/MP3H primers. From the 156 studied patients, 79 (50.6\%) presented positive parasite direct search (PD), 81 (51.9\%) had positive Montenegro skin test (MST), and 90 (57.7\%) presented PD and/or MST positive. The PCR was positive in all of the positive-PD patients (100\% sensitivity), in $91.1 \%$ of the positive PD and/or MST patients, and in $27.3 \%$ of the patients that presented negative $P D$ and positive MST. The PCR positivity was similar to the $P D(\mathrm{P}=0.2482)$ and inferior to the MST $(\mathrm{P}=0.0455)$, and to the PD/MST association $(\mathrm{P}=0.0133)$. The high PCR sensitivity, and positivity in those cases where the PD was negative, highlights the importance of this technique as an auxiliary tool for the diagnosis of ATL.
\end{abstract}

Key words: American tegumentary leishmaniasis - laboratorial diagnosis - polymerase chain reaction

Leishmaniasis is one of the highest incident infectiousparasitic diseases in the world. According to World Health Organization, more than 12 million people in 88 countries are affected by the disease, and about 350 millions more are at risk to contract the infection (WHO 2005). The annual incidence is estimated in 1-1.5 million cases of the tegumentary leishmaniasis and 500 thousand cases of the visceral form (WHO 2005). From the total cases of the recorded tegumentary leishmaniasis, $90 \%$ occurred in only six countries: Iran, Saudi Arabi, Syria, Afghanistan, Brazil, and Peru (WHO 2005). The American tegumentary leishmaniasis (ATL) occurs in the Americas, going from the South of the United States up to the North of Argentina. In 2003, in Brazil, 26,185 confirmed cases occurred, being 849 cases in the South region, and 826 of them in the state of Paraná (Ministério da Saúde 2005).

The similarities among the clinical manifestations of ATL and other diseases require the performance of laboratorial exams for quick beginning of treatment (Isaza et al. 2002). The laboratorial diagnosis performed by conventional techniques has various limitations. The direct parasite search (PD) by microscopy in skin lesion samples, despite of being quick and having low cost has limited sensitivity, particularly in chronic lesions (Belli et al. 1998, Piñero et al. 1999, Singh \& Sivakumar 2003). The in vitro culture techniques are susceptible to microbiological contamination (Belli et al. 1998). The Montenegro skin test detects the late hypersensitivity reaction to the Leishma-

Financial support: CNPq, Araucária Foundation +Corresponding author: tgvsilveira@uem.br

Received 14 February 2006

Accepted 3 May 2006 nia antigens, but do not distinguish between current infection and past infection (Belli et al. 1998, Weigle et al. 2002). The serological techniques have some inconveniences as cross reaction between Leishmania antigens and other parasites as Trypanosoma cruzi (Vexenat et al. 1996), as well as low sensitivity due to low antibody titers, a characteristic of tegumentary leishmaniasis (Badaró $\&$ Reed 2001)

In the last years, molecular techniques have been used for the detection and identification of Leishmania in culture, biopsy, scrapes, blood, and phlebotomine (Marques et al. 2001). The polymerase chain reaction (PCR) is able for detecting so little quantities as 1 phentogram $\left(10^{-15} \mathrm{~g}\right)$ of Leishmania DNA, equivalent to 1/10 of parasite (Gontijo \& Carvalho 2003), offering an alternative way for the demonstration of parasites in clinical samples (Belli et al. 1998, Medeiros et al. 2002, Oliveira et al. 2005). The objective of this work was to compare the PCR in lesion scrapping with other techniques used for the ATL diagnosis in patients in the northern region of Paraná.

\section{MATERIALS AND METHODS}

Studied population - From August 2003 to October 2004, 156 patients from the 15th Health Regional of Maringá with cutaneous lesions suspected of ATL, after clinical evaluation, were sent to the Teaching and Research Laboratory in Clinical Analysis at Maringá State University, which is a center of reference for the ATL laboratorial diagnosis of the Health Ministry. After the performance of laboratorial exams, the patients returned to the doctor's for the recommended treatment. Informed consent was obtained from all patients. This work followed Resolution 196/96 from the Health National Council from Brazil's Health Ministry, and was approved by the Permanent Ethics Committee in Research involving Human Beings from the Maringá State University (no. 120/2003). 
Biological samples - It was collected material of the border of the lesion from all of the patients by scrapping, using a metal scraper free from DNA. Lesion samples were distributed in four areas of three slides for PD. Lesions samples were also placed in two tubes free from RNAses and DNAses with $100 \mu \mathrm{l}$ STE buffer $(10 \mathrm{mM}$ TRIS; $1 \mathrm{mM}$ $\mathrm{Na}_{2}$ EDTA. $\left.\mathrm{H}_{2} \mathrm{O} ; 0.1 \mathrm{M} \mathrm{NaCl} ; \mathrm{pH} 8.0\right)$ and were stored at $-20^{\circ} \mathrm{C}$, for posterior DNA extraction.

Conventional diagnosis methods - For PD, the slide containing lesion material were stained by the Giemsa method, and analyzed for the presence of Leishmania sp. amastigotes forms. The MST was accomplished by inoculation of $0.1 \mathrm{ml}$ of antigen [Leishmania (Leishmania) amazonensis $-40 \mu \mathrm{g} / \mathrm{ml}$ proteic nitrogen] on the patient"s forearm region. The reading was performed after $48 \mathrm{~h}$, being considered positive the enduration of medium diameter $\geq 5 \mathrm{~mm}$. The reagent for MST was supplied by Immunobiological Production and Research Center (CPPI), Paraná State Health Secretariat.

$P C R$ - For the DNA extraction of lesion samples, the tubes containing lesion scraping material were incubated at $95^{\circ} \mathrm{C}$ for $30 \mathrm{~min}$, in the Biometra PC Thermocycler, centrifuged at $13,000 \mathrm{~g}$ for $1 \mathrm{~min}$, and the supernatant was transferred to another tube, and stored at $4^{\circ} \mathrm{C}$ until use.

For DNA amplification it was used the MP1L (5' - TAC TCC CCG ACA TGC CTC TG - 3') and MP3H (5' - GAA CGG GGTTTC TGT ATG C - 3') primers described by Lopez et al. (1993), that amplify a fragment of 70 base pairs of the mini-circles present in the kDNA of members of Leishmania (Viannia) subgenus. The PCR reaction mixture $(25 \mu \mathrm{l})$ contained $1 \mu \mathrm{M}$ of each one of the primers (Invitrogen ${ }^{\circledR}$ ), $0.2 \mathrm{mM}$ dNTP (Invitrogen ${ }^{\circledR}$ ), 2U of Taq DNA Polymerase $\left(\right.$ Invitrogen $\left.{ }^{\circledR}\right), 3 \mathrm{mM}$ of $\mathrm{MgCl}_{2}, 1 \times$ enzyme buffer and $5 \mu \mathrm{l}$ of the extracted DNA. The DNA amplification was carried out in a Biometra PC Thermocycler, using an initial heating of $95^{\circ} \mathrm{C}$, for $5 \mathrm{~min}$. Later on, there were made thirty cycles, each divided into three phases: denaturation $\left(95^{\circ} \mathrm{C}\right.$ $-1.5 \mathrm{~min})$, annealing $\left(56^{\circ} \mathrm{C}-1.5 \mathrm{~min}\right)$ and elongation $\left(72^{\circ} \mathrm{C}\right.$ $-2 \mathrm{~min}$ ). Then, the material was kept at $72^{\circ} \mathrm{C}$ during $10 \mathrm{~min}$ and the amplified product was stored at $4{ }^{\circ} \mathrm{C}$ until analysis. Amplified samples were submitted to electrophoresis in a 3\% agarose gel stained with $0.1 \mu \mathrm{g} / \mathrm{ml}$ ethidium bromide, at $10-15 \mathrm{~V} / \mathrm{cm}$. For each six samples to be amplified, were added one positive control and one negative control of amplification. The presence of amplified DNA bands was accomplished in a UV transilluminator (Macro Vue UV-20 Hoefer).

Statistical analysis - The PCR positivity comparative analysis in relation to the PD and MST methods was accomplished by the McNemar test, because the test pairs were performed in species of the same patient, using the Statistica 6.0 Software.

\section{RESULTS}

From the 156 patients with cutaneous lesions, 103 $(66 \%)$ were male. The patients' age average was 43.4 (varying from 2 to 86 ) and the average lesions evolution time was 79 days (varying from 12 to 1095 days). The PD was positive in $79(50.6 \%)$ patients, and the MST in 81 (51.9\%)
(Table I). Together, the two tests were positive to $57.7 \%$ of the suspected patients.

The PCR with lesion scraping material using the heat DNA extraction method and amplification with the MP1L/ MP3H primers was able to detect the DNA of $15 \mathrm{~L}$. (V.) braziliensis promastigotes, equivalent to 0.75 parasites $/ 5$ $\mu \mathrm{l}$ of the sample for amplification (Fig. 1A). Fig. 1B shows examples of patients' lesions scrapping PCR.

The 156 patients suspected of ATL were divided into four groups according to the PD and MST results (Table II). The PCR was positive in $52.6 \%(82 / 156)$ of the patients suspected of having ATL, being positive in 79 patients that had positive PD (100\% sensitivity) and in three patients (27.3\%) who had positive MST only. The PCR did not detect any of the 66 patients who had both negative PD and MST. Among the patients with positive PD and/or MST, 91.1\% (82/90) showed positive PCR. The PCR positivity was similar to the $\mathrm{PD}(P=0.2482)$ and lower than the MST $(P=0.0455)$ or the PD and MST together $(P=$ $0.0133)$.

\section{TABLE I}

Parasite direct search and Montenegro skin test positivity from patients with suspected and confirmed American tegumentary leishmaniasis (ATL)

\begin{tabular}{lc}
\hline Diagnostic test & ATL suspected $(\mathrm{n}=156)$ \\
\hline PD alone & $79(50.6 \%)$ \\
MST alone & $81(51.9 \%)$ \\
PD plus MST & $90(57.7 \%)$ \\
\hline
\end{tabular}

PD: parasite direct search; MST: Montenegro skin test.

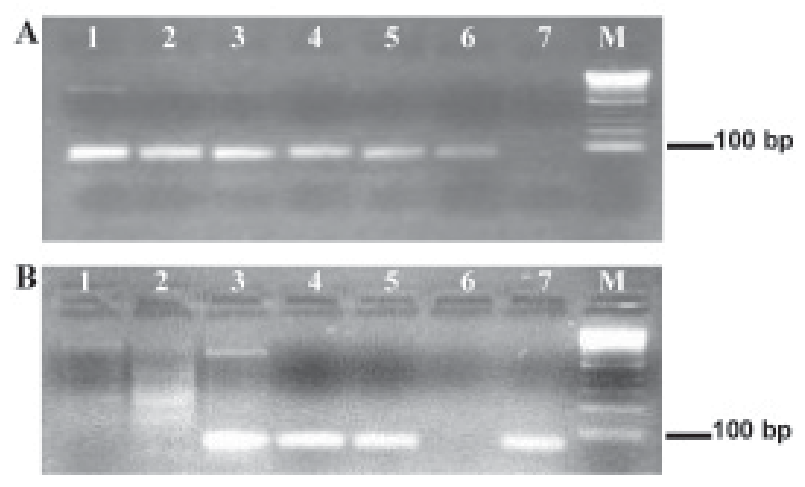

Fig. 1: representative gel showing 70 basepairs (bp) fragment of the k-DNA minicircle region of Leishmania (Viannia) subgenus, amplified by polymerase chain reaction (PCR) using MP1L/MP3H primers. A: PCR sensitivity using DNA extracted through heating and amplified by MP1L/MP3H primers. DNA of different concentrations of $L$. (V.) braziliensis was extracted and used as target DNA. Lanes 1, 2, 3, 4, 5, 6, 7, DNA from 25, 12, 6, 3, 1.5, 0.75 and 0.38 promastigotes, respectively. M: molecular weight standards; B: lanes - 1 and 2: negative samples of human lesions; 3, 4, and 5: positive samples of human lesions; 6: negative control (PCR reaction mixture); 7: positive control [DNA extracted from $L$. (V.) braziliensis promastigotes]; M: molecular weight standards. 
TABLE II

Polymerase chain reaction (PCR) results in lesions from 156 patients suspected of American tegumentary leishmaniasis (ATL) according to the parasite direct search (PD) and Montenegro skin test (MST) results

\begin{tabular}{lcccc}
\hline Group (PD/MST) & Total of patients & \multicolumn{2}{c}{ PCR of lesion } & Positivity of PCR (\%) \\
\cline { 3 - 4 } & & Positive & Negative & 100 \\
\hline Positive/Positive & 78 & 78 & 0 & 100 \\
Positive/Negative & 1 & 1 & 8 & 27.3 \\
Negative/Positive & 11 & 3 & 66 & 0 \\
Negative/Negative & 66 & 0 & 74 & 52.6 \\
\hline Total & 156 & 82 & 0
\end{tabular}

$P=0.2482$, McNemar test, PCR versus PD; $P=0.0455$, McNemar test, PCR versus MST; $P=0.0133$, McNemar test, PCR versus $\mathrm{PD}+\mathrm{MST}$.

\section{DISCUSSION}

ATL is considered a serious public health problem worldwide. In Brazil, the disease has been found in all states (Ministério da Saúde 2005). The importance of the ATL laboratorial diagnosis is due to the similarity of clinical signs to other diseases, and the need of quickly initiating the adequate treatment (Isaza et al. 2002). The ATL diagnosis is commonly performed by parasite direct search in lesion, antibody search, besides the late hypersensitivity reaction (Montenegro skin test) (Ramírez et al. 2000, Badaró \& Reed 2001, Hepburn 2003, Singh \& Sivakumar 2003). Nevertheless, these techniques are very limited.

The concluding laboratorial ATL diagnosis is accomplished by parasite demonstration in lesions as the PD of amastigote forms in material obtained by scrapping, aspiration or edge biopsy and stained by Giemsa or Leishman (Gontijo \& Carvalho 2003). The chance of finding the parasite is inversely proportional to the time of lesion evolution. The sensitivity to the method in ATL cases due to $L$. braziliensis is about $100 \%$ in the first two months of evolution according to Furtado (1980). In this work, the PD was positive in $50.6 \%$ of the patients. Considering the 57 patients that had a lesion of up to two months, 54 (94.7\%) had a positive PD. The positivity found in PD was similar to the described results in literature (33 a 77\%) (Marques et al. 2001).

The MST is routinely used for the ATL diagnosis because it is a test of easy performance, however, it is not able to distinguish past from current infection (Marques et al. 2001). The MST was positive in $51.9 \%$ of the patients and the association of PD and MST was useful to diagnose ATL in $57.7 \%$ of suspected patients $(n=156)$. In a previous work, Silveira et al. (1999) showed that the association of PD and MST confirmed the ATL diagnosis in $73.6 \%$ of the suspected patients. These data show that clinical screening needs improving.

At the present work it was used the PCR for ATL diagnosis in patients with suspicious lesions. Since in the north and northwestern regions of Paraná the majority of Leishmania isolates $(98.7 \%$ ) has been identified as L. (V.) braziliensis (Silveira et al. 1996, 1999), it was decided to use the MP1L/MP3H primers described by Lopez et al. (1993), that amplify a fragment of 70 base pairs of minicircle region present in the kDNA of members of Leishmania
(Viannia) subgenus. However, it is necessary to remember that these primers are specific for Leishmania (Viannia), and this PCR can be negative if the patient was infected by L. (L.) amazonensis.

The decision of using material collected by scrapping from the lesion's internal edge was due to the fact that it is a less invasive and quicker method, and has good positivity in parasite direct search and in PCR (Belli et al. 1998, Isaza et al. 2002). The PCR using lesion scrapping presented $100 \%$ of sensitivity when compared with direct microscopy, according to Belli et al. (1998). Isaza et al. (2002) have obtained $90.6 \%$ of PCR positivity in biopsies and $80.5 \%$ in lesion scrapping. Among the ATL (positive PD and/or MST), the results showed $91.1 \%$ of positivity, similar to the ones found by Lopez et al. (1993), Rodriguez et al. (1994), Pirmez et al. (1999), Marques et al. (2001), and Weigle et al. (2002). In all cases where one of the conventional exams was positive, and the lesion PCR negative, another lesion material sample was extracted and amplified. This procedure contributed for the detection of one patient infected with $L$. (V.) braziliensis.

The PCR positivity reached $100 \%$, when both the PD and MST were positive and also for one patient that presented PD positive and MST negative. This patient was HIV positive, a fact that explains the lack of cell immune response against the parasite antigens.

In the 11-patient group where only the MST was positive, the PCR showed three positive results $(27.3 \%)$, differing from the positivity $(60 \%)$ found by Marques et al. (2001). The low positivity found in this group can be explained by the fact that the MST can detect past infections (Oliveira et al. 2005), besides the possibility of crossreactions with other infections, like sporotrichosis, as reported by Barros et al. (2005). It is important to highlight that from the 8 PCR-negative patients, one had been previously treated, and four had borderline MST. The PCR did not detect any case in the negative PD and MST patients' group, suggesting that these patients' lesions could be of other etiology, showing the necessity of greater attention in the clinical examination of the patients.

It can be concluded that neither the PD nor the MST are efficient enough for the ATL diagnosis, corroborating with the results by Lopez et al. (1993) and Marques et al. (2001). The PCR with lesion scrapping showed $100 \%$ of 
sensitivity when compared with PD, $91.1 \%$ of positivity in positive PD and/or MST patients, and $27.3 \%$ in patients with only the MST positive. In this context, the PCR can be an alternative for the ATL diagnosis in cases of negative PD, especially in patients with chronic lesions who received specific treatment or in recurrent cases, which can occur in patients infected by $L$. (V.) braziliensis.

\section{REFERENCES}

Badaró R, Reed SG 2001. Leishmanioses. In EW Ferreira, SLM Ávila (eds), Diagnóstico Laboratorial das Principais Doenças Infecciosas e Auto-imunes, 2nd ed., Guanabara Koogan, Rio de Janeiro, p. 255-262.

Barros MBL, Schubach A, Francesconi-do-Valle AC, GutierrezGalhardo MC, Schubach TMP, Conceição-Silva F, Salgueiro MM, Mouta-Confort E, Reis RS, Madeira MF, Cuzzi T, Quintella LP, Passos JPS, Conceição MJ, Marzochi MCA 2005. Positive Montenegro skin test among patients with sporotrichosis in Rio de Janeiro. Acta Trop 93: 41-47.

Belli A, Rodriguez B, Aviles H, Harris E 1998. Simplified polymerase chain reaction detection of New World Leishmania in clinical specimens of cutaneous leishmaniasis. Am J Trop Med Hyg 58: 102-109.

Furtado T 1980. Critérios para o diagnóstico da leishmaniose tegumentar americana. An Bras Dermatol 55: 81-86.

Gontijo B, Carvalho MLR 2003. Leishmaniose tegumentar americana. Rev Soc Bras Med Trop 36: 71-80.

Hepburn NC 2003. Cutaneous leishmaniasis: an overview. $J$ Postgraduate Med 49: 50-54.

Isaza DM, Arboleda M, Restrepo M, McCann SHE, Barker DC 2002. Validation of the polymerase chain reaction for the diagnosis of human cutaneous leishmaniasis in northwest Colombia. Trans $R$ Soc Trop Med Hyg 96: 165-168.

Lopez M, Inga R, Cangalaya M, Echevarria J, Llanos-Cuentas A, Orrego C, Arevalo J 1993. Diagnosis of Leishmania using the polymerase chain reaction: a simplified procedure for field work. Am J Trop Med Hyg 49: 348-356.

Marques MJ, Volpini AC, Genaro O, Mayrink W, Romanha AJ 2001. Simple form clinical sample preservation and Leishmania DNA extraction from human lesions for diagnosis of American cutaneous leishmaniasis via polymerase chain reaction. Am J Trop Med Hyg 65: 902-906.

Medeiros ACR, Rodrigues SS, Roselino AMF 2002. Comparison of the specificity of PCR and the histopathological detection of Leishmania for the diagnosis of American cutaneous leishmaniasis. Braz J Med Biol Res 35: 421-424.

Ministério da Saúde 2005. Secretaria de Vigilância em Saúde. http://dtr2001.saude.gov.br/svs/epi/situacao_doencas/ transmissiveis00.htm.

Oliveira JGS, Novais FO, Oliveira CI, Cruz Junior AC, Campos LF, Rocha AV, Boaventura V, Noronha A, Costa JML, Barral A 2005. Polymerase chain reaction (PCR) is highly sensitive for diagnosis of mucosal leishmaniasis. Acta Trop 94: 55-59.

Piñero J, Martinez E, Pacheco R, Aragon Z, De Armas F, Del Castilho A, Valladares B 1999. PCR-ELISA for diagnosis of mucocutaneous leishmaniasis. Acta Trop 73: 21-29.

Pirmez C, Da Silva Trajano V, Paes-Oliveira Neto M, Da Cruz AM, Gonçalves-da-Costa SC, Castanho M, Degrave W, Fernandes O 1999. Use of PCR in diagnosis of human American tegumantary leishmaniasis in Rio de Janeiro, Brazil. J Clin Microbiol 37: 1819-1823.

Ramírez JR, Agudelo S, Muskus C, Alzate JF, Berberich C, Barker D 2000. Diagnosis of cutaneous leishmaniasis in Colombia: the sampling site within lesions influences the sensitivity of parasitologic diagnosis. J Clin Microbiol 38: 3768-3773.

Rodríguez N, Guzman B, Rodas A, Takiff H, Bloom BR, Convit J 1994. Diagnosis of cutaneous leishmaniasis and species discrimination of parasites by PCR and hybridization. $J$ Clin Microbiol 32: 2246-2252.

Silveira TGV, Arraes SMAA, Bertolini DA, Teodoro U, Lonardoni MVC, Roberto ACBS, Ramos M, Nerilo Sobrinho A, Ishikawa E, Shaw J 1999. Observações sobre o diagnóstico laboratorial e a epidemiologia da leishmaniose tegumentar no Estado do Paraná, sul do Brasil. Rev Soc Bras Med Trop 32: 413-423.

Silveira TGV, Teodoro U, Lonardoni MVC, Guilherme ALF, Toledo MJO, Ramos M, Arraes SMAA, Bertolini DA, Spinoza RP, Barbosa OC 1996. Aspectos epidemiológicos da leishmaniose tegumentar em área endêmica do Estado do Paraná, Brasil. Cad Saúde Públ 12: 141-147.

Singh S, Sivakumar R 2003. Recent advances in the diagnosis of leishmaniasis. J Postgraduate Med 49: 55-60.

Vexenat AC, Santana JM, Teixeira AR 1996. Cross-reactivity of antibodies in human infections by kinetoplastid protozoa Trypanosoma crui, Leishmania chagasi and Leishmania (Viannia) braziliensis. Rev Inst Med Trop São Paulo 38 : 177-85.

Weigle KA, Labrada LA, Lozano C, Santrich C, Barrer DC 2002. PCR: based diagnosis of acute and chronic cutaneous leishmaniasis caused by Leishmania (Viannia). J Clin Microbiol 40: 601-606.

WHO - World Health Organization 2005. http://www.who.int/ $\mathrm{tdr} /$ diseases/leish/index.html 